that is that too little attention has been paid to the vitamin intake of athletes and that in fact the feeding of athletes, with its obsession with calories and proteins, is still in a stage from which the science of nutrition began to emerge half a century ago.

\title{
REFERENCES
}

Bicknell, F. \& Prescott, F. (1945). The Vitamins in Medicine. London: Heinemann.

Bourne, G. H. (r943). Unpublished work.

Brunner, H. (194I). Schweiz. med. Wschr. 7r, 715.

Giroud, A. \& Ratsimamanga, A. R. (1939). Arch. Hosp. p. 891.

Glick, D. \& Antopol, W. (1939). F. Pharmacol. 65, 389.

Gounelle, H. (1940). Bull. Soc. méd. Hop. Paris, 56, 225.

Harper, A. A., Mackay, I. F. S., Raper, H. S. \& Camm, G. L. (1943). Brit. med. F. i, 243.

Hills, H. W. (1942). Brit. med. F. ii, 587.

Jetzler, A. \& Haffter, C. (r939). Wien. med. Wschr. 89, 332.

Karpovich, V. \& Millman, N. (1942). New Engl. med. $\mathscr{Y} .226,88$.

Keys, A. \& Henschel, A. F. (I 942). F. Nutrit. 23, 259.

McCormick, W. J. (1940). Med. Rec. 152, 439.

Pilgrim, F. J., Axelrod, A. E. \& Elvehjem, C. A. (1942). F. biol. Chem. 145, 237.

Rugg-Gunn, M. A. (1938). Y. R. nav. med. Serv. 3, 199.

Shock, N. W. \& Sebrell, W. H. (1944). Amer. F. Physiol. x42, 265.

Simonson, E., Enzer, N., Baer, A. \& Braun, R. (1942). F. industr. Hyg. 24, 83.

Sobecki, G. (1939). Med. Prakt. 13, 299.

U.S.A. National Research Council (1945). Repr. nat. Res. Coun., Wash., no. I22.

\section{Choice of Aircrew}

\author{
By C. A. Rumball (Senior Medical Specialist, Royal Air Force) \\ No. 1, C.M.E., R.A.F., Kelvin House, Cleveland Street, London, W.C. I
}

The essential search in the choice of aircrew is to find men who are physically fit for flying duties in any part of the world. They must also possess a stable temperament, and a considerable degree of physical and mental stamina, capable of giving many years of trouble-free service in flying. Finally, they must be psychologically fit with a clear aptitude for the particular branch of aircrew duties in which they are to be trained.

It follows from these considerations that a selection board must know as much as possible about the candidate before making a choice. The aircrew examination is designed to present the board with a composite picture of the candidate's mental and physical make-up, and to predict his suitability for particular aircrew duties. The principles governing examination and selection must be capable of application to large numbers, and must be simple, uniform and objective, and must not require complicated apparatus, except for special investigations such as fitness for high-altitude flying.

The cost of training a pilot is considerable. A direct entrant costs $\oint_{1} 16, \infty 00$ to reach operational standard, and to complete operational training on heavy bomber aircraft raises the cost to $£ 20,000$ (Air Ministry, 1948). By reason of cost, every endeavour is made to avoid selection of faulty candidates which would lead to wasteful training. 


\section{Selection of candidates by examining board}

The investigations of the examining board are grouped under three headings: physical fitness, mental stability and stamina, vocational aptitude. I propose to describe the examinations in that order.

The physical examination. The physical examination comprises a general medical examination of all systems to exclude obvious defects and a chest X-ray to exclude unsuspected pulmonary lesions. If these are satisfactory, physical efficiency tests are applied as a gauge of functional fitness. The special senses are examined in some detail.

Regarding physique, as a general rule, a border-line candidate who is normal or overweight is less likely to prove unsuitable than a border-line underweight candidate (Tredgold, 1936). The significance of body-build and weight in choice of aircrew becomes apparent in the final assessment of doubtful candidates.

Physical efficiency tests. The tendency is to use fewer rather than more tests. They are tests of function and not of disease, but they are useful to detect a falling away in fitness and for assessing return to fitness after an illness or accident.

Information based upon the pulse rate is among the most helpful we possess. A persistent sitting pulse in excess of eighty-four is rarely associated with a good physical efficiency response. A standing pulse taken $5 \mathrm{sec}$. after rising from the sitting position should not exceed the sitting pulse by more than twenty-four beats $/ \mathrm{min}$. The standing pulse taken when it has been constant over $15 \mathrm{sec}$. should not exceed the sitting rate by more than twelve beats/min.

Tests based upon blood pressure have not been proved useful in the selection of aircrew, but special attention is paid to the upper and lower limits of both systolic and diastolic pressures. In general, pressures ranging between $65-90 \mathrm{~mm}$. $\mathrm{Hg}$ diastolic and $105^{-160} \mathrm{~mm}$. $\mathrm{Hg}$ systolic have very little meaning in so far as aircrew are concerned. The average blood pressure of 20,000 R.A.F. pilots was found to be $125 \mathrm{~mm}$. $\mathrm{Hg}$ systolic and $77 \mathrm{~mm}$. Hg diastolic. The upper acceptable limits are $160 / 90 \mathrm{~mm}$. $\mathrm{Hg}$. Diastolic pressures in excess of $90 \mathrm{~mm}$. call for rejection of the candidate, though Savage (quoted by Kureton, 1947) found that the average diastolic pressure of fifty-five Marathon runners in 1909 was $93 \mathrm{~mm}$. $\mathrm{Hg}$ and the systolic pressures averaged $127 \mathrm{~mm}$., so that care is required in the interpretation of diastolic pressures around $90-95 \mathrm{~mm}$. $\mathrm{Hg}$. Diastolic pressures around $100 \mathrm{~mm}$. $\mathrm{Hg}$ occurring in trained pilots create a difficult problem. If under 40 years of age they are allowed to continue flying under medical review every 6 months, but after the age of 40 the increasing incidence of arterial disease has made it prudent to stop them flying as sole pilot, or with civil pilots flying for hire or reward, to withdraw their licence. Regarding the lower limits of blood pressure, a systolic pressure of $105 \mathrm{~mm}$. $\mathrm{Hg}$ and of $65 \mathrm{~mm}$. diastolic may be found in very fit men, but if the diastolic pressure is as low as $55-60 \mathrm{~mm}$. $\mathrm{Hg}$ the candidate is usually underweight, with poor efficiency tests, and fails to conform to required standards.

Tests involving spirometry and expiratory force have been abandoned as giving very little useful information. The test which in the experience of the Medical Branch of the Royal Air Force gives more useful information than any other single test in the 
assessment of physical fitness is the $40 \mathrm{~mm}$. Hg endurance test introduced by Flack ( 1920$)$. The test is based upon alterations in pulse rate under the stress of sustaining a $40 \mathrm{~mm}$. column of mercury in a U-tube manometer by a single expiration for as long as is possible. It is also an index of endurance, and the capacity to support discomfort such as breathlessness.

There are four main types of puise response:

(I) A flat curve not rising above seven beats $/ 5 \mathrm{sec}$. interval and sustained for more than $55 \mathrm{sec}$. This type is held to indicate a high degree of cardio-vascular and respiratory efficiency.

(2) A curve rising gradually up to nine beats $/ 5 \mathrm{sec}$. interval. This type is common in the average fit candidate, and is capable of improvement to type $I$ when the subject is in training.

(3) A rapid and sustained rise to ten or more beats $/ 5 \mathrm{sec}$. interval.

(4) A rapid rise as in type 3 but followed by an abrupt fall to a low figure, sometimes as low as five or four beats $/ 5 \mathrm{sec}$. interval.

Both the two latter curves indicate poor functional efficiency. Type 3 is common after an illness, especially of a toxic kind: type 4 is common in constitutionally inefficient types.

Examination of special senses. A candidate who satisfies these efficiency tests is examined for defects in the special senses. The visual acuity must not be less than $6 / 6$ for each eye; colour vision must satisfy the Ishihara (1932) plates and Giles lantern or Martin lantern. Muscle balance allows no more than 6 diopters of either esophoria or exophoria. Night-vision acuity is tested when difficulty is experienced during night-flying training. Candidates for high-altitude flying require decompression tests equivalent to an altitude of $37,000 \mathrm{ft}$. for $2 \mathrm{hr}$.; any serious sign of decompression sickness calls for rejection of the candidate. This test is not used in the initial selection of aircrew.

Personal and family history of candidate. The second part of the examination is based largely upon the candidate's personal and family history. It gives an insight into his previous reactions and throws light upon his temperament as well as physical and mental stamina. An adequate history includes not only a concise medical biography, but also evidence as to soundness of stock; the sports at which he is proficient or excels; the stresses to which he has been exposed and the manner in which they have been borne. A history of nervous breakdown, of migraine with visual disturbance, recurrent faints of vaso-vagal type, nocturnal enuresis, or sleep-walking after the age of 12 , or asthma persisting after puberty, are definite causes for rejection.

In the family history, a nervous breakdown or psychotic episode in a near relative does not constitute a bar to acceptance, but it makes necessary a very careful scrutiny of the candidate's own psychological make-up. A family history of epilepsy and diabetes is not a bar unless it occurs in two or more close relatives.

Competitive activities such as rowing, boxing, football and long-distance running are presumptive evidence of physical efficiency. Success in boxing may indicate a requisite degree of aggressiveness. Marked ability in fast-moving ball games indicates good co-ordination between hand and eye as well as good ocular balance, both of which are essential for successful handling of an aircraft. 
Tests of vocational aptitude. If a candidate satisfies the board to this stage of the examination he is regarded as physically fit and temperamentally suitable for aircrew duties. The third part of the examination is designed to reveal innate trends and natural ability, made manifest by a battery of twenty-three tests (Parry, 1948). This battery yields measures of aptitude for each aircrew category and enables prediction of suitability without wasteful training. For example, prediction for navigator is particularly accurate because of the high educational factor necessary in this branch of aircrew, and educational attainment is one of the easiest things to test. Pilot prediction, on the other hand, is particularly difficult, because there is no satisfactory yardstick to use as a measure; nevertheless, prediction excludes much wasteful training of aircrew pilots. All the prediction tests have been validated against training results, and have more than proved their worth.

The battery of tests comprises eighteen paper tests and five apparatus tests. As a result of the tests a candidate is selected for one of the five aircrew categories: pilot, flight engineer, navigator, air bomber and air gunner.

The factors tested include general intelligence, educational attainments, judgement, reasoning, aviation-information, general mathematics, table reading, mechanical comprehension, technical information, instrument comprehension, map reading and aircraft-silhouette recognition. The apparatus tests are largely designed to reveal co-ordination between hands, feet and eyes. The recording is entirely objective and is electrically controlled to eliminate the personal factor. The battery of tests is spread over a period of 2 days to eliminate fatigue which could create false recordings in otherwise suitable candidates.

On completion of the third part of the examination the board has all the information it requires to make its choice of aircrew.

\section{REFERENCES}

Air Ministry (1948). Personal communication from Department of Science ( $3 b$ ).

Flack, N. (1920). Spec. Rep. Ser. med. Res. Coun., Lond., no. 53.

Ishihara, S. (1932). Tests for Colour Blindness, 6th ed. Tokyo: Kanehara and Co.

Kureton, T. E. (1947). Physical Fitness, Appraisal and Fudgement. London: Henry Kimpton.

Parry, H. W. (1948). Personal communication from Air Ministry, Department of Science (4).

Tredgold, H. A. (1936). The Medical Examination for Fitness for Flying, A.P. no. 130, 4th ed. London:

H.M. Stationery Office.

\section{The Nutrition of Athletes}

By A. Abrahams, 86 Brook Street, Grosvenor Square, London, W. I.

In order to provide a connecting link between scientific contributions and conclusions derived from practical experience of athletes, I suggest a consideration of three fundamentals:

(I) To what extent is it necessary to provide athletes in training with a high calorie diet?

(2) In the composition of such a diet should any particular foodstuffs predominate, and is any specific advantage derived from flesh foods and especially meat? 